\title{
THE HISTORICAL VIDEO GAME
}

\section{AS A FORM OF MEMORY \\ El videojuego histórico como forma de memoria}

Alberto Venegas

\section{Universidad de Murcia}

correodealbertovenegas@gmail.com - https://orcid.org/0000-0002-5621-7749

Fecha recepción: 15.07.2019/ Fecha aceptación: 15.12.2019

\section{Resumen}

En este artículo vamos a definir al videojuego histórico como memoria frente a las definiciones de éste medio como historia o forma historiográfica. Para llegar a esta definición vamos a estudiar diferentes casos de videojuegos históricos como el estadounidense Call of Duty WWII (Sledgehammer, 2017), el también estadounidense, aunque de origen iraní, 1979 Revolution: Black Friday (iNK Studios, 2014) y el austriaco (y sirio) Path Out (Causa Creations, 2017) junto a otros títulos que nos sirvan para ofrecer el contexto necesario. Junto a la observación directa de éstos acudiremos al tra-

\begin{abstract}
In this article, I shall define the historical video game as a form of memory, as opposed to definitions of this medium as history or a form of historiography. To arrive at this new definition, I will examine the case of several different historical video games such as the American Call of Duty WWII (Sledgehammer, 2017), the also American -albeit of Iranian origin - 1979 Revolution: Black Friday (iNK Studios, 2014) and the Austrian (and Syrian) Path Out (Causa Creations, 2017), together with other games that serve to provide the necessary context. Direct observation
\end{abstract}


bajo de Le Goff (1991), Hobsbwam (2014), Aguilar Fernández (2008), Traverso (2011) y Todorov $(2008,2013)$ para determinar si, efectivamente, el videojuego histórico puede considerarse memoria y que consecuencias conlleva para su estudio dicha condición del videojuego histórico como memoria en lugar de historia.

\section{Palabras clave}

Memoria, videojuego, memoria oficial, memoria colectiva, memoria individual. of these will be combined with an examination of the work of Le Goff (1991), Hobsbwam (2014), Aguilar Fernández (2008), Traverso (2011) and Todorov $(2008,2013)$ to determine whether, indeed, the historical video game can be considered memory rather than history, and if so, what the consequences of this are for its study.

\section{Keyword}

Memory, video games, institutional memory, collective memory, individual memory. 


\section{Introducción}

El 5 de abril de 2016 iNK Studios publicó el videojuego 1979 Revolution: Black Friday. El título proponía al jugador recorrer las calles de Teherán durante la revolución islámica de Irán. Su llegada al mercado venía precedida de una ardua polémica mantenida entre los responsables de la obra, hijos de exiliados iraníes durante dicha revolución, y el gobierno iraní. Ambos grupos, el estudio de desarrollo afincado en Nueva York y el Estado islámico de Irán, proponían un recuerdo diferente del acontecimiento. Las dos memorias colisionaban en el recuerdo del objetivo revolucionario, los métodos para conseguirlo y las consecuencias de la implantación de un nuevo orden en Irán. Un contraste que llevó al segundo a prohibir el videojuego en el país persa y no permitir traspasar su frontera a los miembros del estudio neoyorquino. Esta decisión la hizo pública Hassan Karimi, director de la NFGC iraní (National Foundation for Computer Games) quien añadió en su declaración:

Iranians will quickly realize the hostile intentions and objectives of the developer if they see the game (...) Games like this can poison the minds of the youth and young adults about their country by means of false and distorted information, and also damage their spirits. ${ }^{1}$

1979 Revolution: Black Friday representa un acontecimiento histórico y lo recuerda bajo el punto de vista de sus creadores. Su memoria choca frontalmente con el discurso del gobierno de Irán. No es el único caso de memorias encontradas en el videojuego. El gobierno chino ha censurado distintos títulos ambientados en la Segunda Guerra Mundial por presentar al Tíbet, Sinkiang y Manchuria como países independientes. ${ }^{2}$ El videojuego estadounidense Call of Duty WWII (Sledgehammer, 2017), de acuerdo a sus responsables, trata de mantener el recuerdo de la Segunda Guerra Mundial vivo. ${ }^{3}$ Un

1. Redacción de Tehran Times, "Iran plans to block websites offering 1979 Revolution”. En línea en: https:// www.tehrantimes.com/news/300689/Iran-plans-to-block-websites-offering-1979-Revolution. [Consulta: $1 / 6 / 2019]$

2. T. Donovan, Replay. La Historia de los Videojuegos, Sevilla, 2018, 368.

3. L. Parker, "The Weight Of History: Exploring The Real-Life Inspirations Behind Call of Duty: WW2”. En línea: https://www.gamespot.com/articles/the-weight-of-history-exploring-the-real-lifeinsp/1100-6453656/. [31/5/2019] 
recuerdo basado en las obras anteriores más populares, ${ }^{4}$ el beneplácito de las instituciones del país, ${ }^{5}$ opuesto al recuerdo de los combatientes ${ }^{6}$ y con origen en las generaciones posteriores a Vietnam ${ }^{7}$ y la idea de "guerra buena». ${ }^{8}$

Tal y cómo podemos observar en estos tres casos relacionados con Irán, China y Estados Unidos existen distintas formas de acceder al pasado basadas en intereses particulares, especialmente políticos y nacionalistas. Recuerdos que chocan entre sí y crean memorias fuertes, débiles, literales, ejemplares, estéticas, individuales, colectivas u oficiales. Los autores de estos videojuegos no buscan el pasado por la curiosidad y el ideal de verdad, rasgos citados por Paul Veyne como característicos de la Historia de los historiadores, ${ }^{9}$ sino que tratan de crear una representación del ayer condicionada por sus intereses particulares inventando literariamente el pasado en lugar de situar la historia en un relato documentado con pretensión de verdad y universalidad. Más la finalidad del placer del juego.

\section{Objetivo}

La intención de este trabajo es precisamente ésta: demostrar que el videojuego es una forma de recuerdo del pasado y no de historificación del pasado. Esta definición del videojuego como memoria se nos antoja más útil para su estudio como objeto de investigación y, a la vez, más cómoda y útil para investigar junto a él, como sujeto, nuevas formas de acercarnos al pasado. Además, esta definición nos permitirá estudiar la memoria colectiva, definida por Burke como: «una útil abreviatura para resumir el complejo proceso de selección e interpretación en una fórmula simple y pone[r] de relieve el paralelismo entre las formas en que el pasado se registra y se recuerda ${ }^{10}$ de una manera más ágil y relevante dada la importancia mediática del videojuego en nuestra contemporaneidad.

No negamos que el videojuego pueda ser historia, otros han investigado este camino con éxito. ${ }^{11}$ Sin embargo entendemos que el videojuego actual dista mucho de encontrarse en ese lugar. En cambio, su estado presente encaja de una manera más adecuada en la definición de memoria entendida como «representaciones colectivas del pasado tal como se forjan en

4. A. Venegas Ramos, "Entre el cine y el videojuego. Ética y estética en las producciones sobre la Segunda Guerra Mundial”, en J. F. Jiménez Alcázar y F. G. Rodríguez, Videojuegos e Historia: Entre el ocio y la cultura. Colección Historia y Videojuegos, No5, Murcia, 2018.

5. C. Groux, "How the new Call of Duty reinvents old battlegrounds". En línea en: https://www.newsweek. com/new-call-duty-ww2-battlegrounds-705567. [Consulta: 3/7/2019].

6. P. Fussell, Tiempos de guerra: conciencia y engaño en la Segunda Guerra Mundial, Barcelona, 2003, 179.

7. P. Aguilar Fernández, Políticas de la memoria y memorias de la política. Madrid, 2008, 31.

8. D. Ramsay, American Media and the Memoria of World War II, Nueva York, 2016.

9. J. Le Goff, Pensar la historia. Modernidad, presente y progreso, Barcelona, 1991, 35.

10. P. Burke, Formas de historia cultural, Madrid, 2011, 68.

11. A. Chapman, Digital Games as History: How Videogames Represent the Past and Offer Access to Historical Practice, Nueva York, 2016. 
el presente». ${ }^{12}$ Así entendido, el medio digital se antoja una herramienta de vital importancia para conocer el «proceso de selección e interpretación del pasado y poner de relieve el paralelismo entre las formas en que el pasado se registra y se recuerda». Una memoria que cobra diferentes formas en el medio del videojuego que la aleja de la condición de historia, ya que «la memoria es la vida», lo que la expone...

...a la dialéctica del recuerdo y de la amnesia, inconsciente de sus sucesivas deformaciones, vulnerable a todos los usos y manipulaciones, susceptible de largas latencias y de repentinas revitalizaciones. Ahora bien, este vínculo vivido en el presente eterno no puede asimilarse a la historia, representación del pasado que, aunque problemática y siempre incompleta, se quiere objetiva y retrospectiva, fundada en la distancia. La memoria es «afectiva y mágica», encargada de sacralizar los recuerdos, mientras que la historia es una visión secular del pasado, sobre el que construye «un discurso crítico». ${ }^{13}$

Por tanto, definir el videojuego histórico como una representación colectiva del pasado realizada en el presente nos permite emplear el medio digital como fuente histórica y a la vez como elemento fundamental de rememoración y conmemoración en el siglo XXI. Este objetivo que proponemos puede tener un recorrido aún más extenso y ser aplicable al resto de ficciones históricas existentes en el mercado, desde el cine, muy utilizado en este trabajo por la innegable relación con el videojuego de contenido histórico, ${ }^{14}$ hasta el cómic o la televisión. Un objetivo más extenso que puede alcanzarse debido a que este trabajo no se detiene en el estudio exhaustivo de la forma, tema ya tratado en anteriores trabajos, ${ }^{15}$ sino en el contenido y las formas de recordar y reconstruir el pasado que tiene lugar en cada una de las ficciones seleccionadas.

\section{Metodología}

Para tratar de demostrar este objetivo transitaremos dos vías, la primera de ella es la observación directa de tres videojuegos concretos, Call of Duty: WWII y 1979 Revolution: Black Friday. Cada uno de ellos representa un tipo de memoria aquí considerada, oficial y no oficial, fuerte y débil, hegemónica y subalterna. Ambas toman parte de la memoria estética,

12. E. Traverso, El Pasado, instrucciones de uso: historia, memoria, política, Buenos Aires, 2011, 16.

13. E. Traverso, El Pasado...op. cit., 29.

14. Véase el capítulo dedicado al videojuego por Debra Ramsay en su obra referente al cine estadounidense de la Segunda Guerra Mundial American media and the memory of the World War Two "Brutal Games" donde afirma que: "Saving Private Ryan 's influence on the transmedia construct of World War II extends beyond film and television into what Sheldon Brown terms "the medium of our moment"-the videogames industry" en D. Ramsay, American media and the memory of the World War Two, Nueva York, 2015, 162.

15. A. Venegas Ramos, "La problemática de la imagen como forma de transmisión histórica en la cultura digital”. Revista Caracteres. Estudios culturales y críticos de la esfera digital. 7(2), 2018, 35-56. 
compuesta de «retrolugares», ${ }^{16} \mathrm{y}$ examinada como parte integral de la cultura de masas contemporánea. Junto a ellos incluiremos otros videojuegos con la intención de ofrecer el contexto necesario. Estas observaciones se intercalarán con los ensayos más destacados sobre el campo de la memoria, especialmente los desarrollados por Le Goff, Hobsbwam, Aguilar Fernández, Traverso y Todorov.

\section{Memoria oficial: el caso de Call of Duty: WWII}

Call of Duty: WWII es un videojuego de acción con una perspectiva en primera persona desarrollado por el estudio estadounidense Sledgehammer Games y publicado por la empresa, también estadounidense, Activision. El título está ambientado en la Segunda Guerra Mundial, concretamente en el año 1944 durante el avance aliado por Francia tras el desembarco de Normandía. El protagonista del título es el soldado estadounidense Ronald «Red» Daniels, miembro de la primera división de infantería e integrante de un pelotón formado por los soldados Robert Zussman, el soldado Drew Stiles, el técnico Frank Aiello, el sargento William Pierson y el teniente Joseph Turner. Todos ellos de nacionalidad estadounidense.

La intención del videojuego es, de acuerdo a sus responsables, recordar lo sucedido: «Nos dimos cuenta de que tenemos que seguir contando estas historias para que el mundo no olvide lo que sucedió, y así no vuelva a suceder». ${ }^{17}$ Para ello contaron con numerosos recursos, desde la colaboración con veteranos de guerra, la visita a los lugares donde ocurrieron los hechos representados ${ }^{18}$ y la grabación de armamento real para captar el auténtico sonido de armas y vehículos de la época con la intención de «recrear esos sonidos de la manera más auténtica posible». ${ }^{19}$ Todo ello con el beneplácito del gobierno, encargado de ceder las licencias oficiales para representar uniformes, armas, vehículos, etc., propiedad del Ejército de los Estados Unidos.

Esta pretensión de verdad y ejemplaridad se rompe en determinadas cuestiones, como la representación de la Shoah. Éste se incluyó, de acuerdo a sus responsables, como consecuencia de la demanda de los usuarios ${ }^{20}$ y sirvió de fuerte atractivo mediático y comercial. ${ }^{21}$ Dos razones que encajan a la perfección dentro de la tesis propuesta por Norman G. Finkels-

16. A. Venegas Ramos, "Retrolugares, definición, formación y repetición de lugares, escenarios y escenas imaginados del pasado en la cultura popular y el videojuego". Revista de historiografía. 28, 2018, 323-346.

17. L. Parker, “The Weight Of History..., op. cit.

18. L. Parker, “The Weight Of History..., op. cit.

19. A. Andersen, "Creating Call of Duty WWII's Historic Sound - an in-depth interview with Dave Swenson”. En línea: https://www.asoundeffect.com/call-duty-wwii-sound/. [Consulta: 31/5/2019].

20. A. Rosenberg, "Call of Duty: WWII won’t ignore the Holocaust anymore”. En línea: https://mashable. com/2017/04/26/call-of-duty-wwii-holocaust-interview/\#fc3CjjxTAiqV. [Consulta: 1/7/2019].

21. H. Nielsen, "Call of Duty: WWII could be the most important game of all time for Historians". En línea: https://www.theguardian.com/technology/2017/apr/25/call-of-duty-wwii-historians-video-gamesactivision. [Consulta: 12/6/2019]. 
tein ${ }^{22}$ para describir el uso público de la memoria de la Shoah. Finkelstein argumenta que el genocidio judío se ha explotado como negocio. De acuerdo a este investigador la Shoah apareció en la vida estadounidense tras la guerra árabe-israelí de junio de $1967^{23}$ bajo la apariencia de dos principios:

Dos son los dogmas fundamentales que sustentan la estructura del Holocausto: (1) el Holocausto constituye un acontecimiento histórico categóricamente singular; (2) el Holocausto marca el clímax del eterno e irracional odio gentil a los judíos. ${ }^{24}$

Así es como aparece en Call of Duty WWII, como un hecho singular, la prueba de esta afirmación es la inexistencia en esta obra de ficción, o en cualquier otro videojuego que represente y reconstruya este período, de cualquier otro «Holocausto» como el romaní, el eslavo o el chino. Esta excepcionalidad guarda relación con aquello que Todorov denominaba memoria literal, es decir un suceso (...) preservado en su literalidad (...) permaneciendo intransitivo y no conduciendo más allá de sí mismo. ${ }^{25}$

La Shoah que aparece en el videojuego de Sledgehammer no sucedió. Reconstruir un campo de concentración y exterminio nazi desierto mientras varios soldados estadounidenses lo recorren asombrados ante el terror y la violencia irracional del Tercer Reich es una reificación del pasado. Mostrar, sin molestar a nadie, algo que ningún videojuego había mostrado jamás. Una idea expresada por Condrey durante una entrevista al medio especializado Polygon: «Creo que todos temíamos que si no lo manejábamos con la delicadeza que requería, saliera mal». ${ }^{26}$ Fueron con tanto miedo y delicadeza que al final, no mostraron nada. Una decisión que Condrey achaca a seguir el mismo camino que las grandes producciones cinematográficas ${ }^{27}$ y que les sirvió para presentar la representación de la Shoah como un gran logro en el medio. Anzuelo que picaron diversas publicaciones, como el periódico The Guardian quien publicaba un amplio reportaje sobre el videojuego: «Call of Duty: WWII could be the most important game of all time for historians ${ }^{28}$ aunque más tarde, cuando lo jugaron, enmendaron este titular con otro reportaje titulado «Call of Duty WWII is about killing for fun. Why pretend otherwise?» ${ }^{29}$ Un proceso que ilustra la conversión de la memoria en espectáculo, tal y como nos advertía Traverso:

22. N. G. Finkelstein, La industria del Holocausto, Madrid, 2014.

23. N. G. Finkelstein, La industria del... op. cit., 27.

24. N. G. Finkelstein, La industria del... op. cit., 45.

25. T. Todorov, Los abusos de la memoria, Barcelona, 2013, 33.

26. B. Kuchera, "Why Call of Duty: WWII struggled to show the horrors of the Holocaust". En línea: https://www.polygon.com/2017/11/3/16604330/call-of-duty-wwii-holocaust. [Consulta: 13/6/2019].

27. B. Kuchera, "Why Call of Duty..., op. cit.

28. H. Nielsen, "Call of Duty: WWII..., op. cit.

29. K. Stuart, "Call of Duty WWII is about killing for fun. Why pretend otherwise?" En línea: https:// www.theguardian.com/technology/2017/apr/27/call-of-duty-wwii-activision-realism-killing. [Consulta: 16/6/2019]. 
Ese fenómeno revela indudablemente un proceso de reificación del pasado, es decir, su transformación en objeto de consumo, estetizado, neutralizado y rentabilizado listo para que la industria del turismo y del espectáculo lo recupere y utilice. ${ }^{30}$

En esta representación de la Shoah existe una clara desconexión entre el pasado recordado y representado por el videojuego y la historia documentada. La inclusión del genocidio en este ejemplo sigue una senda definida por la existencia de una memoria estética que ha sustituido, en los medios de comunicación de masas, a la historia. Ya que otra de las razones que explican el formato escogido por Call of Duty WWII para representar el genocidio judío se encuentran en la memoria estética del mismo. Existen, en la cultura mediática de masas occidentales, dos mediaciones maestras acerca de este hecho que son ineludibles para representar la persecución judía en la pantalla: la serie de televisión Holocausto (Gerald Green, 1978) y La lista de Schindler (Steven Spielberg, 1993). Tal y como explica Sánchez-Biosca para el primer caso:

Aun cuando el proceso es muy complejo, lo cierto es que el docudrama televisivo Holocausto (1978) dio forma narrativa, plástica y argumentativa a una tendencia que se había puesto probablemente en marcha en los Estados Unidos con el filme El diario de Anna Frank (1959) y que logró asentar un modelo de larga duración en la memoria del Holocausto, justo el mismo año en que Jimmy Carter creaba una comisión encabezada por Ellie Wiesel destinada a preparar un memoria que acabaría siendo el United States Holocaust Museum de Washington ${ }^{31}$.

El modelo erigido por la serie de televisión fue recogido, y actualizado, por Spielberg en su película, la cual ha sido vista en más de 675 millones de hogares. Un dato que la ha convertido en la producción estadounidense con mayor audiencia para un programa no deportivo. ${ }^{32}$ De acuerdo a Shlomo Sand la televisión, la imagen mediática en general, se ha convertido en la principal fuente de conocimiento del ciudadano medio sobre la Shoah y los horrores perpetrados por el régimen nazi ${ }^{33}$. Esta situación ha provocado el nacimiento de una memoria estética acerca del acontecimiento que debe ser reproducida literalmente para asegurar la semejanza con lo ocurrido. De acuerdo a Sand esta reproducción se amplía con un ritmo de dos películas u obras mediáticas al año ${ }^{34}$, una producción abultada que no ha logrado profundizar ni mejorar el conocimiento que se tiene sobre el suceso, sino que tan solo ha logrado perpetuarlo estéticamente en los medios de comunicación de masas ${ }^{35}$. Un hecho al que viene a sumarse Call of Duty WWII al reproducir, de nuevo, todos los retrolugares contenidos en la mediación maestra de La lista de Schindler:

30. E. Traverso, El Pasado...óp. cit., 14.

31. V. Sánchez-Biosca, Cine de historia, cine de memoria, Madrid, 2006, 155.

32. V. Sánchez-Biosca, Cine de historia... op. cit., 151 (a fecha de 2006).

33. S. Sand, El siglo XX en pantalla, Barcelona, 2003, 352.

34. S. Sand, El siglo XX... op. cit., 339.

35. S. Sand, El siglo XX... op. cit., 347. 
La representación de los judíos como polvo de seres humanos, no sólo en el exterminio sino también en la operación de salvamento, parece corresponderse con la nueva concepción que el realizador-productor todopoderoso de Hollywood tiene del martirio judío. La condición evidente para este modo de representación era que todos los perseguidos fueran exclusivamente judíos (en la película no aparecen otras víctimas) y que todos fueran buenos y justos (incluidos los policías del gueto, que se comportan como monaguillos) ${ }^{36}$.

En el videojuego los judíos están tan representados como polvo que éstos no llegan ni tan siquiera a verse, sin embargo aparecen como los únicos perseguidos, el objetivo principal del nazismo. Otro de los retrolugares impuestos por la serie de televisión Holocausto. De acuerdo a Sand el programa televisivo consiguió cambiar la percepción acerca del nazismo y representarlo como exclusivamente antijudío. ${ }^{37}$ En el videojuego este retrolugar se antoja transparente como el cristal. No existe, en ningún título ambientado en la Segunda Guerra Mundial, ninguna mención al exterminio de otras comunidades que no sean la judía. Una serie decisiones que guardan relación con la americanización del Holocausto, como bien mencionaba Sánchez-Biosca. Es decir, la representación del genocidio judío como medio para enseñar los valores tradicionales estadounidenses ${ }^{38}$.

Por lo tanto, Sledgehammer Games y Activision, no deseaban mostrar la Shoah de la manera más auténtica posible como si querían hacer con el sonido de la época o la geografía de las batallas. No había un ideal de verdad en su búsqueda del pasado. Su intención era reproducir una serie de representaciones anteriores que guardan relación con la forma en la que los gobiernos de los Estados Unidos de América han decidido conmemorar y recordar el genocidio judío durante la Segunda Guerra Mundial bajo sus propios intereses.

La decisión anterior, reapropiarse del pasado y emitirlo siguiendo líneas oficiales, la podemos encontrar en otros apartados del videojuego, como su faceta multijugadora. La campaña para más de un usuario de Call of Duty WWII permite controlar a cualquiera de los dos bandos descritos por el juego: aliados o «eje», aunque las opciones quedan restringidas a estadounidenses, británicos, soviéticos y miembros de la resistencia francesa para los aliados y soldados de la Wehrmacht alemana para el «eje», despojados de la esvástica como símbolo descriptivo y sustituida por la Cruz de Hierro. Esta decisión elimina una gran cantidad de países participantes en el conflicto de tanto calado como Japón, Italia, Polonia, Canadá, Hungría, Yugoslavia, etc, etc. Además también oculta a otras tropas alemanas como la Waffen-SS de una manera voluntaria en este caso concreto para evitar, de acuerdo a las palabras de los responsables del título, glorificar a este grupo. ${ }^{39}$

36. S. Sand, El siglo XX... op. cit., 354.

37. S. Sand, El siglo XX... op. cit., 335.

38. V. Sánchez-Biosca, Cine de historia... op. cit., 139.

39. E. Kain, “This Is Why There Are Black Nazis And No Swastikas In Call Of Duty: World War 2". En línea: https://www.forbes.com/sites/erikkain/2017/06/21/this-is-why-there-are-black-nazis-and-no-swastikas-in-call-of-duty-world-war-2-multiplayer/\#7fcc61601338. [Consulta: 17/6/2019]. 
Numerosos historiadores como Wolfram Wette, ${ }^{40}$ Sönke Neitzel y Harald Welzer, ${ }^{41}$ Christian Ingrao ${ }^{42}$ o Browning Christ ${ }^{43}$ han demostrado que tanto la Wehrmacht como las Waffen-SS fueron responsables conjuntos de algunas de las atrocidades bélicas del conflicto. Otra polémica que vino a sumarse a la desaparición de la esvástica como forma de representación del ejército nazi, justificado por Michael Condrey, co-fundador de Sledgehammer, con el mismo argumento que el utilizado para explicar la eliminación de las Waffen-SS, esquivar la glorificación nazi y evitar recordar el genocidio perpetrado contra el pueblo judío. ${ }^{44}$ Sin embargo la esvástica si aparecía en otros títulos de la saga y en otros muchos videojuegos ambientados en el conflicto. Y no solo aparece en otros juegos sino que en este en concreto hacen aparición otra serie de símbolos ligados al nazismo desde sus raíces, como el águila. De acuerdo a Rosa Sala Rose el águila:

...solía ser asociada al Sol, el fuego y la luz, así como al principio fecundador y masculino. En opinión de Carl Gustav Jung, el sentido último de este símbolo es la idea de altura. Todos estos significados, de por sí perfectamente coherentes con los ideales de las cosmovisión nazi, fueron incorporados por ésta al viejo simbolismo imperial... ${ }^{45}$

Nos encontramos, en definitiva, con una memoria selectiva cuyo objetivo fundamental es la reificación de la misma dentro del contexto del discurso oficial sobre el acontecimiento histórico. Una decisión que también encuentra su raíz en la pantalla, donde, de acuerdo a Shlomo Sand, la división militar del ejército de Alemania tomó forma muy pronto:

En las muchas películas bélicas producidas en los países occidentales durante los años cincuenta, entre las cuales hay no pocos relatos del heroísmo de la resistencia antialemana o de los campos de concentración, el nazismo aparece desligado de cualquier vínculo histórico y social. Siguiendo el ejemplo del cine alemán de ese período, el cine internacional presenta la Wehrmacht y los ciudadanos alemanes «de a pie» como ajenos a la empresa del III Reich, y a menudo incluso como si fueran las víctimas de la persecución del régimen. Los mandos del ejército se oponen al alma noble y generosa; tan sólo las SS y la Gestapo son extraños monstruos en guerra contra todo el mundo, como si los nazis hubieran desembarco desde otro planeta y se hubieran vuelto a marchar en cuanto fueron derrotados definitivamente. El objetivo de este imaginario cinematográfico era despejar el camino para la reintegración de los alemanes en la gran familia de las naciones «ilustradas». En efecto, Alemania desempe-

40. W. Wette, La Wehrmacht: los crímenes del ejército alemán, Barcelona. 2010.

41. S. Neitzel y H. Welzer, Soldados del Tercer Reich: testimonios de lucha, muerte y crimen, Barcelona. 2014.

42. C. Ingrao, Creer y destruir. Los intelectuales en la máquina de guerra de las SS, Barcelona, 2017.

43. C. Browning, Aquellos hombres grises. El batallón 101 y la Solución Final en Polonia, Barcelona, 2019.

44. W. Yin-Poole, "How Call of Duty: WW2 handles swastikas and female soldiers". En línea: https:// www.eurogamer.net/articles/2017-06-19-lets-talk-call-of-duty-ww2-swastikas-and-female-soldiers. [Consulta: $1 / 7 / 2019]$.

45. R. Salas Rose, Diccionario crítico de mitos y símbolos del nazismo, Barcelona, 2003. 
ñaba un papel de primer orden en la lucha contra el comunismo, y era conveniente volver a trazar las fronteras cinematográficas del bien y del mal en función de las nuevas necesidades estratégicas $^{46}$ (pp. 281-282).

Un escenario muy diferente al pretendido por sus autores, quienes afirmaron que la campaña de Call of Duty «WW2's trataba de contar una auténtica historia de la Segunda Guerra Mundial». ${ }^{47}$ Esta paradoja entre la memoria y la historia, de acuerdo a Le Goff:

...proviene del contraste entre el éxito de la historia en la sociedad y la crisis del mundo de los historiadores. El éxito se explica por la necesidad que tienen las sociedades de nutrir su búsqueda de identidad, de alimentarse de un imaginario real; y las solicitaciones de los medios masivos hicieron entrar a la producción histórica en el movimiento de las sociedades de consumo. ${ }^{48}$

Frente a todas estas evidencias se nos antoja muy difícil definir Call of Duty: WWII como historia. No existe una pretensión de verdad, su desarrollo no está movido por la curiosidad. No existe un acercamiento a las fuentes documentales. Su contenido está condicionado por la imagen, ${ }^{49}$ la lógica del mercado y la propia forma del videojuego. ${ }^{50}$ Sin embargo se nos antoja muy fácil definirlo como memoria. De acuerdo a Todorov en la memoria:

...la elección de los hechos y su disposición jerárquica no la llevan a cabo eruditos especialistas (...) sino grupos influyentes de la sociedad que pretenden defender sus intereses. El objetivo prioritario de estos grupos no es conocer el pasado con exactitud, sino lograr que los demás reconozcan su lugar en la memoria colectiva, y por lo tanto en la vida social del país. ${ }^{51}$

La selección de los hechos que componen la memoria de la Segunda Guerra Mundial en Call of Duty: WWII no la han llevado a cabo especialistas, sino los miembros del estudio de desarrollo. Su objetivo no ha sido conocer el pasado, como hemos podido demostrar, sino «seguir contando estas historias para que el mundo no olvide lo que sucedió, y así no vuelva a suceder». Unas historias que sirven para «que los demás reconozcan su lugar en la memoria colectiva, y por lo tanto en la vida social del país».

46. S. Sand, El siglo XX... op. cit., 281-282.

47. W. Yin-Poole, "How Call of Duty..., op. cit.

48. J. Le Goff, Pensar...op. cit., 142.

49. A. Venegas Ramos, "La problemática de la imagen como forma de transmisión histórica en la cultura digital". Revista Caracteres. Estudios culturales y críticos de la esfera digital. 7(2), 2018, 35-56.

50. A. Venegas Ramos, "Emergencia y formación de subjetividades históricas en los videojuegos de acción contemporáneos. El caso del desembarco de Normandía". Tropelías: Revista de teoría de la literatura y literatura comparada. 31, 2019, 116-131.

51. T. Todorov, El miedo a los bárbaros, Barcelona, 2008, 93. 
El recuerdo de la Segunda Guerra Mundial se ha convertido en Estados Unidos en mito nacional ${ }^{52}$ y ha servido para justificar ${ }^{53}$ y explicar nuevos conflictos. ${ }^{54}$ Un recuerdo promocionado por las instituciones del país, tanto del ejército, cediendo las licencias de sus armas, vehículos y símbolos a la empresa de desarrollo, mecanismo fundamental para entender la supervisión del cuerpo militar de los productos culturales donde se les representa, ${ }^{55}$ como del gobierno, a través de la colaboración con los estudios y la cesión de expertos. ${ }^{56}$

Por lo tanto se hace evidente que la obra de Sledgehammer Games y Activision no es historia, sino memoria «dominante, las que más representadas están en los medios de difusión», ${ }^{57} \mathrm{y}$ «hegemónica [la que] prevalece de forma mayoritaria en el grupo que estemos investigando», ${ }^{58}$ lo que la convierte en memoria oficial, ya que está sostenida por instituciones estatales. ${ }^{59}$ Esta concepción del videojuego Call of Duty: WWII no como historia sino como memoria oficial

...se refiere, pues, a un trabajo de homogeneización de las representaciones -siempre selectivas- del pasado, las cuales suelen revestir un fuerte componente mitológico y sobre las que se sustentan las identidades colectivas, sean éstas de tipo nacional o no. Aun cuando originalmente pudieron estar configuradas por los recuerdos individuales de algunos miembros del grupo, con el paso del tiempo las élites culturales -impulsoras de iniciativas políticas basadas en la difusión de rasgos étnicos o culturales- acaban elaborando un discurso simplificado y común sobre el pasado, apto para el consumo de los miembros de la identidad compartida y sumamente manipulable por las élites políticas. ${ }^{60}$

Queda patente entonces la condición de este videojuego como discurso memorístico favorable a intereses particulares. Una situación que puede extenderse al resto de grandes producciones videolúdicas ambientadas en la Segunda Guerra Mundial y desarrolladas en Estados Unidos como en otros países. Esta memoria ha obtenido tanta fuerza, gracias a los medios de comunicación de masas, que ha comenzado a ser adoptada por otros países como Francia, donde el título Steel Division: Normandy 44 (Eugen Systems, 2017) ha reproducido el discurso estadounidense oficial para conseguir ser consumido en el mercado anglosajón. ${ }^{61}$ Una decisión que también ha sido tomada por estudios británicos, ucranianos o polacos.

52. D. Ramsay, American...op. cit.

53. C. Boggs y T. Pollard, The Hollywood War Machine: U.S. Militarism and Popular Culture, Nueva York, 2015.

54. J. Dower. Culturas de guerra. Pearl Harbor, Hiroshima, 11S, Irak. Barcelona, 2012.

55. P. Fussell, Tiempos de...op. cit., 240.

56. M. Castells, Comunicación y poder, Barcelona, 2009, 350.

57. P. Aguilar Fernández, Políticas de...op. cit., 24.

58. P. Aguilar Fernández, Políticas de...op. cit., 24.

59. E. Traverso, El Pasado...op. cit., 2011, 53.

60. P. Aguilar Fernández, Políticas de...op. cit., 50.

61. J. Wilson, "Steel Division: Normandy 44 is Paradox Interactive's grand entrance into tactical combat". En línea: https://venturebeat.com/2017/03/01/steel-division-normandy-44-is-paradox-interactives-grandentrance-into-real-time-tactical-combat/. [Consulta: 23/6/2019]. 
El videojuego como memoria oficial es, por tanto, una representación del pasado, o del presente, auspiciada por instituciones estatales con motivos particulares, generalmente de tipo nacionalista. El recuerdo está condicionado por el discurso oficial y la memoria dominante, la más aceptada por la sociedad en la que nace representada con profusión en los medios de comunicación de masas. Suele contener un pasado sin aristas, homogeneizado y estilizado con la intención de ser aceptado por la mayor audiencia posible. Un pasado reificado, es decir, convertido en objeto de consumo.

\section{Memoria no oficial: el caso de 1979 Revolution: Black Friday}

Durante una entrevista a la Radio Nacional Pública de Estados Unidos el creador de 1979 Revolution: Black Friday afirmó que la intención de su título era permitir al jugador recorrer física y moralmente la revolución iraní. ${ }^{62}$ La revolución que presenta el título está basada, parcialmente, en los recuerdos de Navid Khonsari, tal y como él afirma en la misma entrevista:

On the streets of the summer of 1978, when I was in Tehran with my grandfather, I could feel the hope. I could feel the possibility that change could come. People were happy. They were hugging each other. They believed that they were about to change their country, their world.

And then six, eight months later, when the protests became violent and soldiers were shooting up in the air, I also remember the emotions that I had when my mother would tell me to get down on the ground because of a stray bullet that might come through the window of our thirdfloor apartment. ${ }^{63}$

La partida sigue este guion. Durante los primeros compases de la partida el jugador tomará el control del personaje protagonista, Reza Shirazi, un joven fotógrafo que desea inmortalizar la revolución con su cámara. A medida que avanza ésta Reza comenzará a adentrarse en los entresijos de la insurgencia y tomará contacto con los diferentes grupos que formaron parte de ella. Un movimiento imparable que le llevará, finalmente, a escoger entre la violencia o el pacifismo, entre las piedras o las palabras. A través de pequeños minijuegos y respuestas múltiples con un tiempo de respuesta limitado el protagonista podrá navegar en torno a la revolución y recorrerá una línea cuyo origen es la esperanza en el cambio y su final la intransigencia de los diferentes grupos y los disparos de los soldados.

Esta forma de percibir la revolución, como la esperanza que desembocó en tiranía, forma parte de la memoria heredada del creador del título, Khonsari. El binomio «revolución - esperanza de cambio» fue el detonante del videojuego. Tal y como el autor afirma fue

62. Redacción de NPR. "Already A Movie Topic, Iran's Revolution Is Now A Video Game”. En línea: https://www.npr.org/2016/04/20/474935464/already-a-movie-topic-iran-s-resolution-is-a-videogame?t=1559375230711. [Consulta: 31/5/2019].

63. Redacción de NPR. “Already A Movie Topic, Iran’s Revolution...”, op. cit. 
el estallido de la Primavera Árabe el fuego que prendió la mecha de su trabajo en 1979 Revolution. ${ }^{64}$ Sin embargo, la reconstrucción del contexto se apoya en documentos y personajes de la época, como la del torturador Asadollah Lajevardi. Éste es el encargado de interrogar al protagonista, Reza. El título transcurre durante el interrogatorio, bajo la forma de recuerdos del protagonista. Los recuerdos-momentos jugables se desarrollan mediante espacios interactivos intercalados entre 1978, año en el que transcurre la acción, y 1980, año en el que transcurre el presente del juego. La figura del torturador afín a la revolución islámica no es el único elemento real. Toda la partida podría resumirse como la ligazón interactiva de las escenas fotografiadas por Michel Setboun, colaborador en el desarrollo del videojuego.

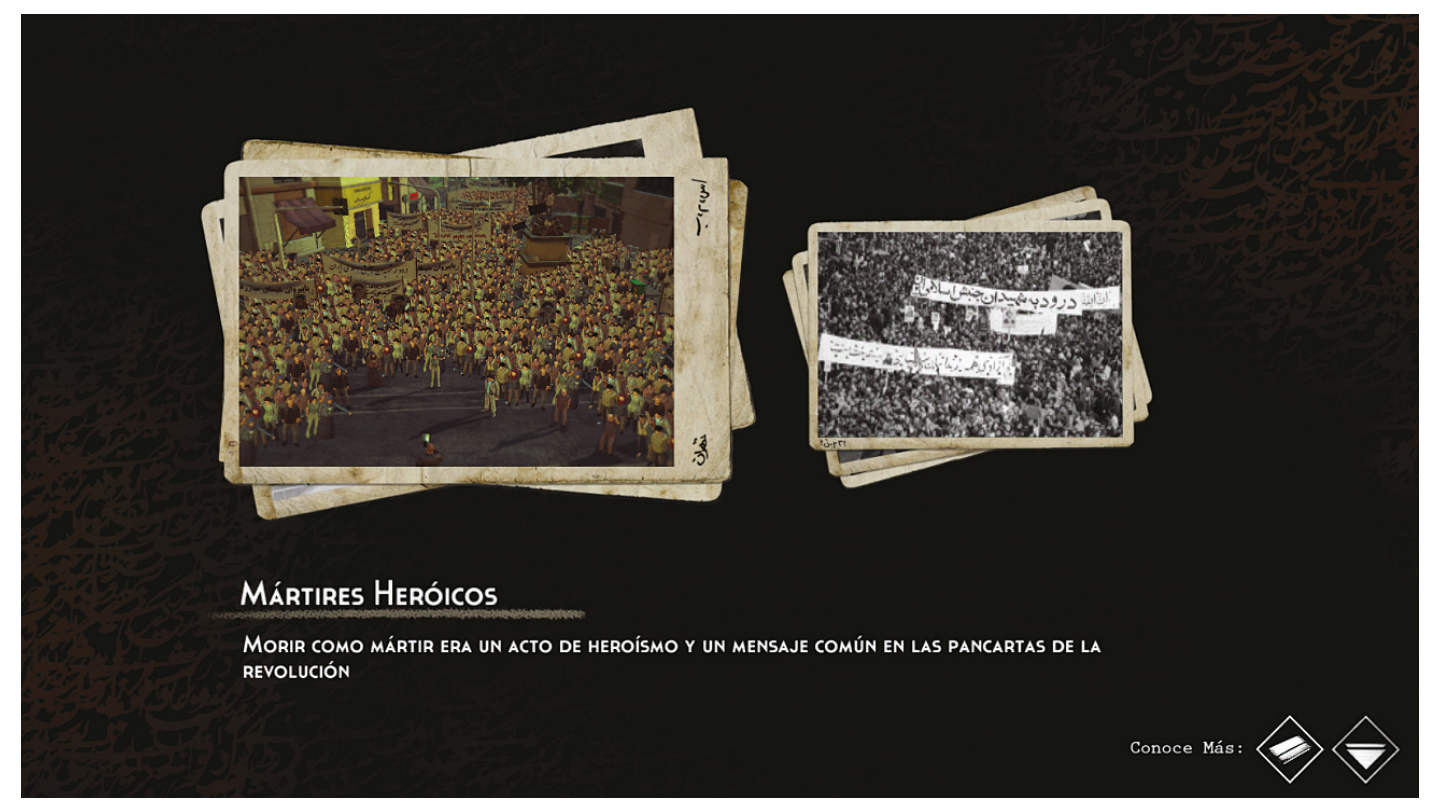

Ilustración 1: Captura de pantalla de 1979 Revolution donde podemos observar una imagen del videojuego frente a la fotografía real de Setboun que la inspiró.

No son éstos los únicos elementos históricos, aparecen discursos reales de Jomeini y otros ayatolás que el jugador deberá buscar, propaganda y carteles de la época añaden una gruesa capa de verosimilitud a los hechos presentados, tal y como afirmaba Khonsari en la misma entrevista:

64. S. Parkin. “A Truly Revolutionary Video Game”. En línea: https://www.newyorker.com/tech/annalsof-technology/a-truly-revolutionary-video-game. [Consulta: 1/6/2019]. 
We reached out to academic scholars, cultural scholars, religious scholars. We've also did over 40 interviews with people from across the spectrum and asked them about their experiences. We also put in home movies, which you can explore, ${ }^{65}$

Existe, por tanto, una clara intención de representar literalmente el Irán de la época y para ello el autor emplea incluso películas caseras de su abuelo a las que el jugador puede acceder durante un momento de la partida. Esta decisión del estudio no permite clasificar el título entre los tipos de memorias distinguidas por Julio Aróstegui, en su obra La historia vivida: sobre la historia del presente (2004): memoria directa: «ligada a la experiencia vital, propia y directa, del individuo o del grupo», memoria heredada: "producto de la transmisión de otras memorias, de la memoria de los predecesores», y memoria institucional: constituida por «lugares de memoria, liturgias y rememoraciones públicas, utilización política, derechos de la memoria y prácticas del olvido» ${ }^{66}$ promovidas por las instituciones estatales y ejemplificada en este trabajo en el videojuego Call of Duty: WWII. En 1979 Revolution se entremezclan todas estos memorias, la percibida por el joven de diez años que, cuarenta años más tarde, desarrollará un videojuego sobre ellos en consonancia con la memoria heredada de su familia y en contraste con la memoria institucional iraní sobre lo sucedido.

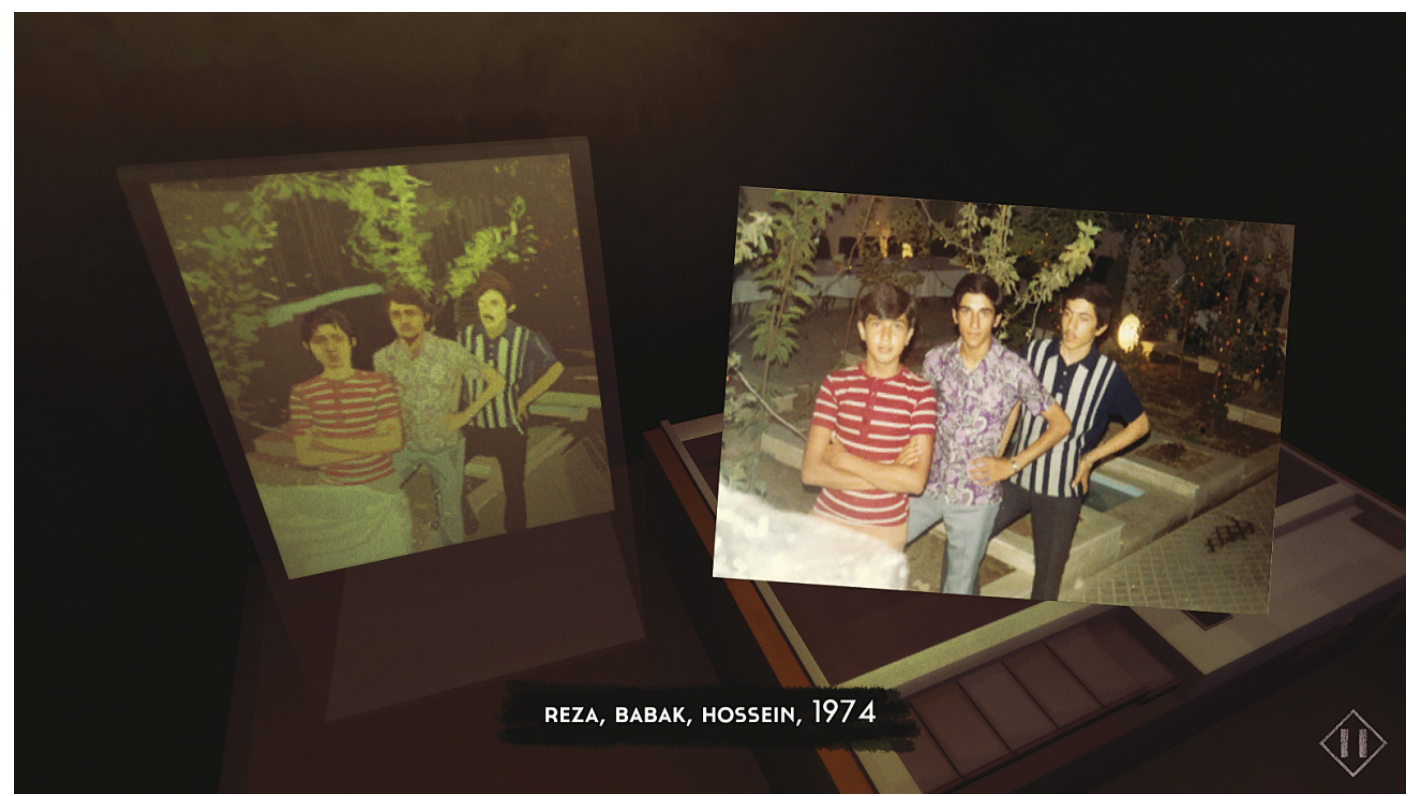

Ilustración 2: Captura de pantalla de 1979 Revolution en el que podemos apreciar una fotografía real de los personajes protagonistas del videojuego.

65. Redacción de NPR. “Already A Movie Topic, Iran’s Revolution...”, op. cit.

66. J. Aróstegui, La historia vivida: sobre la historia del presente, Barcelona, 2004, 160. 
El gobierno iraní, desde que supo de la existencia de este título, ha tratado de entorpecer e incluso prohibirlo en el país asiático. Los dos recuerdos, el de Khonsari y el del gobierno actual iraní, sobre la revolución son contrarios y entran en disputa. La intención del responsable de 1979 Revolution era mostrar los hechos, tal y como él y su familia los recordaba, al público y rescatar su recuerdo de Irán antes de la llegada de los ayatolás:

We wanted people to understand what Iran was like in the '70s, not as a statement against this regime or a statement against what was there, but as an understanding that Iran cannot be depicted by the past 35 years of what we've seen in the news. ${ }^{67}$

El título no es polémico y tampoco toma un partido evidente entre las distintas opciones políticas de la época, aunque trata a algunas más amablemente que a otras. Una decisión tomada por el propio autor para tratar de ampliar la audiencia de su producto. ${ }^{68}$ Sin embargo no son los hechos los que suscitaron la polémica en Irán sino la forma en los que éstos son recordados. La partida establece una clara diferenciación entre reacción, reforma y revolución. La reacción, protagonizada por los simpatizantes del Sah, entre ellos la madre y el hermano del protagonista, la envuelve la brutalidad de las fuerzas policiales y las constantes críticas al gobierno de los Pahleví. La revolución la personifican los dos extremos políticos, los comunistas, representados como intransigentes y violentos en la partida, y los partidarios de Jomeini, ultras religiosos, intransigentes y violentos también, personificados en la figura del torturador, ferviente defensor del ex-líder supremo iraní. Y por último la reforma, personificada en los personajes representados de manera más amable, Babak, Abbas y Bibi. Todos ellos son los estandartes de la palabra y la negociación. Su objetivo es un Irán independiente y democrático. Esta forma de representar la revolución iraní a través de la imagen de una balanza donde los extremos chocan aplastando a la reforma es la causa de la disputa con el gobierno resultante de la revolución iraní.

La rápida expansión del título, empleado desde hace años por diferentes grupos educativos e incluso en centros asociados a la UNESCO, como herramienta educativa e histórica sobre los sucesos acaecidos en Teherán durante 1978 y $1980,{ }^{69}$ ha provocado una disputa por la memoria del evento entre iNK Stories y el gobierno de Irán. La primera noticia sobre el juego en Irán la proporcionó el periódico gubernamental Kayhan. ${ }^{70}$ El noticiario calificó al videojuego de propaganda estadounidense contraria al Estado iraní y calificó a Khonsari

67. Redacción de NPR. “Already A Movie Topic, Iran’s Revolution...”, op. cit.

68. S. Parkin. "A truly..., op. cit.

69. S. Lester, "Iran Chat: Interview with Navid Khonsari, Developer of the Game 1979 Revolution: Black Friday”. En línea: http://www.us-iran.org/news/2016/9/8/iran-chat-interview-with-navid-khonsari-developer-of-the-game-1979-revolution-black-friday. [Consulta: 30/5/2019].

70. T. Lien, “The stressful life of Middle Eastern game developers and reality of their craft”. En línea: https:// www.polygon.com/2012/10/25/3544758/game-development-in-the-middle-east. [Consulta: 29/5/2019]. 
como espía norteamericano que trataba de dañar la reputación del país, ${ }^{71}$ como consecuencia el gobierno le prohibió la entrada a Irán. Para evitar las denuncias iraníes otros miembros del estudio emplearon seudónimos para continuar viajando a su hogar y poder visitar a sus familias. ${ }^{72}$ La repercusión del título fue creciendo a medida que completaba su desarrollo y esa lucha por la memoria se fue engrandeciendo hasta sus últimas consecuencias, la prohibición del título en Irán. ${ }^{73}$ La decisión la hizo pública Hassan Karimi, director de la NFGC iraní (National Foundation for Computer Games) quien añadió en su declaración:

Iranians will quickly realize the hostile intentions and objectives of the developer if they see the game (...) Games like this can poison the minds of the youth and young adults about their country by means of false and distorted information, and also damage their spirits. ${ }^{74}$

La memoria oficial del gobierno iraní sitúa en 1979 uno de los principales hitos de su trayectoria política. La conmemoración celebrada durante este mismo año, el 11 de febrero de 2019, para conmemorar el cuarenta aniversario del hecho histórico refleja la importancia de este recuerdo para el Estado actual. Cientos de miles de iraníes se concentran anualmente en las inmediaciones de la plaza Azadi (libertad) para reafirmar el origen y la fuente de poder del régimen. La geografía de esta elección no es causal, este monumento fue levantado por el Sah en 1970 como símbolo de la modernidad del país y fue rebautizado y resignificado por el nuevo gobierno de Irán como testigo de su victoria. ${ }^{75}$ Una celebración política ${ }^{76}$ y a la vez religiosa que ha trascendido y ha acabado por convertirse en una de las más importantes del país. ${ }^{77}$

La revolución islámica iraní es la primera piedra del régimen de gobierno actual de Irán. La memoria oficial del hecho comienza años atrás, en 1963, año en el que el SAVAK atacó Qom durante la conmemoración del martirio del sexto imán chií, Ya far as Sádiq. Este fue el momento escogido por Jomeini para pronunciar su conocido discurso del día de Ashura condenando al dictador Pahleví y sus soportes políticos, Estados Unidos e Israel. La narrativa oficial continúa su recuerdo de los hechos situando el acento en los actos protagonizados por Jomeini. Este recuerdo oficial describe el estallido de las revueltas de 1978 como consecuen-

71. E. Narcisse, “This Man's Making a Game About His Native Iran. So, Of Course, They Branded Him a Spy”. En línea: https://kotaku.com/this-man-s-making-a-game-about-his-native-iran-so-of-5921067. [Consulta: $1 / 6 / 2019]$.

72. E. Narcisse, "When You Have to Hide Your Identity to Make a Video Game”. En línea: https://kotaku. com/when-you-have-to-hide-your-identity-to-make-a-video-gam-1513466093. [Consulta: 2/6/2019].

73. Redacción de NPR. "Already A Movie Topic, Iran’s Revolution...”, op. cit.

74. Redacción de NPR. "Already A Movie Topic, Iran’s Revolution...”, op. cit.

75. Redacción de The Guardian, "Iranians mark the 40th anniversary of the Islamic revolution in pictures”. En línea: https:/www.theguardian.com/world/gallery/2019/feb/11/iranians-mark-the-40th-anniversary-of-the-islamic-revolution-in-pictures. [Consulta: 3/6/2019].

76. T. Erdbrink. "Iran Celebrates Its Revolution, and Thanks Some Americans". En línea: https://www. nytimes.com/2017/02/10/world/middleeast/iran-revolution-anniversary.html. [Consulta: 3/6/2019].

77. D. Intini, The Politics of National Celebrations in post-revolutionary Iran (Tesis de maestría). Research Master in Middle Eastern Studies, Leiden, 2015. 
cia del posible asesinato del hijo de Jomeini por grupos afines al dictador y la publicación, el 6 de enero de 1978, de distintos artículos de la prensa gubernamental donde se atacaba duramente al ayatolá (Intini, 2015: 68). Fueron estos dos hechos, de acuerdo a la memoria oficial del gobierno, los que condujeron al Viernes Negro, un relato muy diferente al representado en 1979 Revolution, donde ese acontecimiento lo provoca la intransigencia de la dictadura y la desesperación que condujo a la violencia a muchos de los manifestantes. El gobierno, mediante esta selectiva política de recuerdo y olvido trata de eliminar cualquier referencia a los demás grupos políticos que hicieron frente a la dictadura y arrobarse él solo el éxito de la caída de la dinastía Pahleví. ${ }^{78}$ La elección del día 11 de febrero para conmemorar el proceso revolucionario en su conjunto es una decisión que apunta al recuerdo de la caída del Sah como el germen y la fuente justificadora del poder de Jomeini. Durante ese día el ejército declaró su neutralidad tras un fuerte ataque civil a los centros de poder y Jomeini alcanzó el poder sin contrarios ni competidores. Desde el día 1 hasta el día 11, desde el momento en que el ex-líder regresó del exilio hasta el momento en el que alcanzó el poder, se celebran en el país diez días de celebración que terminan con una gran conmemoración en la plaza Libertad.

Sin embargo el hecho diferencial más importante entre las dos memorias de la revolución se encuentra en los momentos posteriores, en el año 1980. Para 1979 Revolution el régimen de los ayatolás impuso una fortísima represión contra las fuerzas adictas al Sah y todos sus contrarios políticos. Esta memoria se representa en la figura del torturador y está condicionada por los recuerdos del responsable del título, cuya familia tuvo que huir del país para continuar con su vida. Todos estos hechos, aunque sucedieron, se encuentran escondidos y relegados en la memoria oficial. ${ }^{79}$

Frente a esta memoria oficial, divulgada desde todos los órganos de poder del gobierno y especialmente desde la educación infantil y juvenil, ${ }^{80} 1979$ Revolution sitúa el acento en los mártires de la revolución que lucharon por un país libre, tanto del Sah como del islam. El videojuego está dedicado a ellos.

78. D. Intini, The Politics...op. cit., 69.

79. S. Talebi, Ghost of Revolution. Rekindled memories of imprisonment Iran, Stanford, 2011.

80. En los libros de texto de octavo grado puede leerse la siguiente descripción de Irán: «Iran is a powerful country in the southwest of Asia and has a special place in the region. The Iranian people, led by Imam Khomeini, fought and won during the Islamic Revolution, to eliminate oppression and establish independence, freedom and an Islamic Republic. The Islamic Revolution of Iran is a model for people in other countries in the world, to rise against the tyranny of the great powers and internal tyranny, and to present a transcendental image of Islam to the world. (...) Today, the Islamic Republic of Iran supports the oppressed people of all countries, especially in Palestine. (...) Although Iran is composed of different ethnic groups, these ethnicities have always been united and have defended the country, en P. Pals, The presentation of the Islamic Republic of Iran in Iranian primary schoolbooks. An interplay of religion and nationalism» (Tesis de maestría). Research Master in Middle Eastern Studies, Universidad de Leiden, 2018, 38-39. 


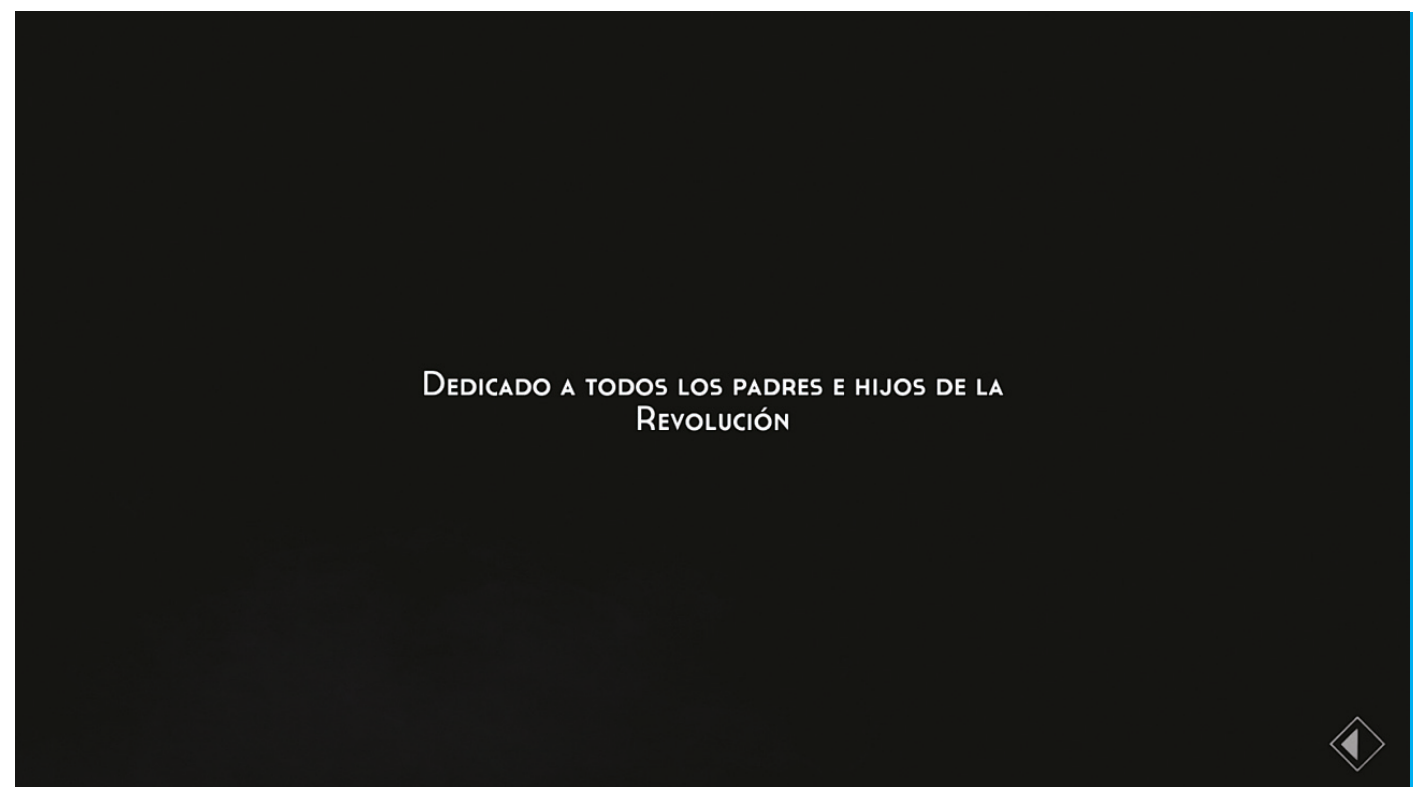

Ilustración 3: Captura de pantalla de 1979 Revolution.

Por lo tanto es fácil comprender la disputa entre las dos representaciones de la revolución, la primera apuntala al poder y se celebra, cada año, de manera literal, ${ }^{81}$ la segunda cuestiona la fuente del poder, critica el régimen impuesto tras la revolución y trata de servir de ejemplo, y advertencia, para otros muchos procesos de cambio, tal y como su responsable no dudaba en afirmar en una entrevista:

We wanted to get micro. We wanted to get you to personally experience the revolution but not just experience the historical highlights of the revolution but actually engage with the dynamics of the different factions that existed in Iran. To deal with people who are wealthy and people who are poor. To deal with people who are educated and who are uneducated. To people who are religious and not religious. Bring those elements in there because that's what's actually going to provide a richer context and, hopefully, then create a greater sense of understanding the reason we embrace the 1979 Revolution is that it's a historical story. A historical story that's unique to Iran but the trajectory of revolutions is universal. That you could apply the French

81. Las celebraciones comienzan en el Aeropuerto Internacional de Mehrabad, en Teherán, justo en el mismo instante en el que Jomeini puso de nuevo el pie en Irán. Durante 2012 el ejército llegó al extremo de emplear un recorte con la forma del ayatolá para simular su descenso del avión y una vez en tierra se le brindaron honores militares D. Intini, The Politics...op. cit., 70. 
Revolution from hundreds of years ago to the Arab Spring. That is interesting for people who are interested in history, in politics, and in the region. ${ }^{82}$

Una intención que guarda una especial relación con la memoria ejemplar descrita por Todorov. Recordar para servir de ejemplo y como advertencia. ${ }^{83}$ La memoria en 1979 Revolution, no es literal aunque parte de fuentes primarias y testimonios directos del suceso. La intención de iNK Studios, tal y como han manifestado en numerosas ocasiones, no reside exclusivamente en tratar de narrar «históricamente» la revolución de Irán sino ofrecer claves y patrones que, de acuerdo a su opinión, se encuentran presentes en otros grandes procesos de cambio. La base de su trabajo es mostrar la violencia y la intransigencia como límites a las opciones de reforma y cambio negociado. E incluso con este objetivo manifiesto aparecen representados la mayoría de los grupos presentes en la revolución bajo tonos grises. El agente de la SAVAK, hermano del protagonista, que busca proteger a su familia a costa de todo. Los intelectuales religiosos que buscan en la fe la tranquilidad y la mesura y no la radicalidad y los excesos. Los liberales que buscan ampliar los derechos y libertades individuales al resto de la población, etc. Todos ellos no se muestran como enemigos o amigos sino como agentes de cambio, aunque si existen villanos, los personajes intransigentes, y héroes, los personajes reformistas.

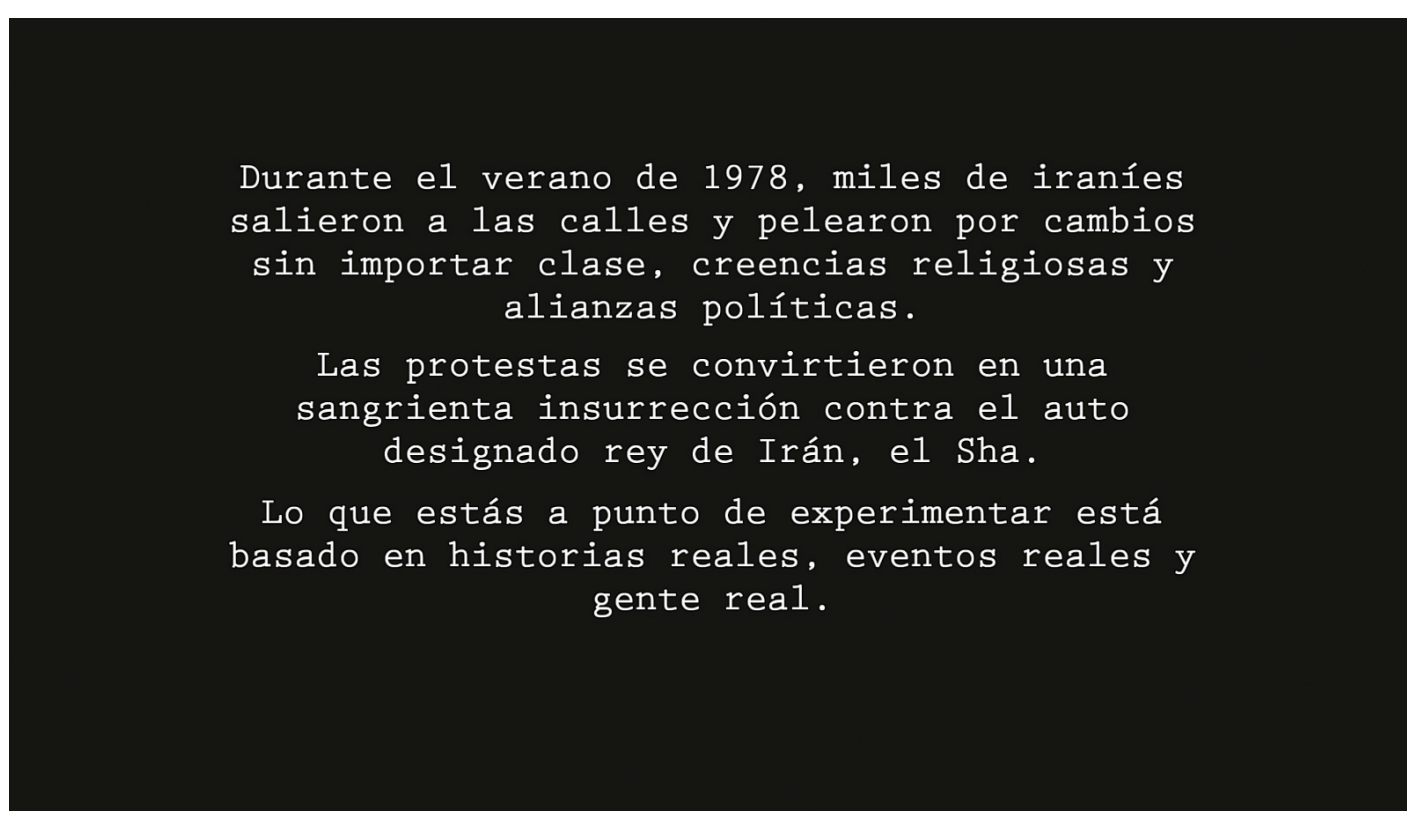

Ilustración 4: Captura de pantalla de 1979 Revolution.

82. D. Tortum, "Interview with Navid \& Vassiliki Khonsari”. En línea: https://docubase.mit.edu/lab/interviews/interview-with-navid-vassiliki-khonsari/. [Consulta: 6/7/2019].

83. T. Todorov, Los abusos...op. cit., 34 . 
Sin embargo la memoria oficial es literal, tal y como hemos podido comprobar en las descripciones de las celebraciones, y busca recordar la Revolución Islámica como fuente de su poder y legitimidad para gobernar. Para ello buscan congelarla en el tiempo y recordarla anualmente con la repetición literal de los hechos que han seleccionado para consolidar su representación y relato del momento histórico.

1979 Revolution puede considerarse memoria colectiva porque no parte de ningún Estado o institución y encaja en la definición ofrecida por Aguilar Fernández en su obra Políticas de la memoria y memorias de la política (2008):

Lo que se entiende por memoria colectiva supone una simplificación de los acontecimientos, en el sentido de que «se enfatizan mucho las narraciones de lo dramático, especialmente de las guerras. Se favorecen las clasificaciones simplistas: héroes y villanos; y las memorias del pasado de una sociedad suelen idealizarse o demonizarse. La dimensión moral de estas memorias es muy importante, puesto que siempre contienen lecciones para el futuro e intentan aportar una imagen coherente de la sociedad. ${ }^{84}$

iNK Studios simplifica los acontecimientos, no menciona el pasado, tampoco la economía del país, no hace mención a ninguna localidad iraní excepto a Teherán. No narra el hecho histórico en su contexto. Enfatiza las narraciones dramáticas, todo lo representado en el videojuego se muestra entre escenas de tortura al protagonista. Existen héroes, el protagonista y los personajes favorables al sistema democrático, y villanos, el torturador y los personajes intransigentes. Todo ello constreñido en un molde moralista y aleccionador auspiciado por la llamada Primavera Árabe.

El apoyo aportado por distintas instituciones a este videojuego ha llevado a la memoria colectiva, la representada por diferentes «miembros de un determinado grupo van construyendo relatos comunes sobre el pasando, partiendo del intercambio entre las memorias individuales y de la información acumulada sobre el hecho en cuestión», ${ }^{85}$ a convertirse en memoria hegemónica y competir con la memoria institucional iraní, como demuestra la lucha del propio gobierno para impedir la expansión del videojuego a y en su país.

La consideración de 1979 Revolution como memoria ofrece una mayor profundidad y calado a la hora de estudiarlo que si lo calificamos como historia, ya que, de acuerdo a Aguilar Fernández:

Las ideas, memorias, identidades que, a pesar de estar sometidas a continua revisión pueden, en distintos momentos, compartir determinados grupos sociales, a muchos nos interesan no por su coherencia interna, ni por su coincidencia con lo realmente acontecido, sino porque son capaces de mover voluntades y de explicar comportamientos de gran relevancia política y social. ${ }^{86}$

84. P. Aguilar Fernández, Políticas...op. cit., 50-51.

85. P. Aguilar Fernández. Políticas...op. cit., 64.

86. P. Aguilar Fernández. Políticas...op. cit., 65-66. 
El videojuego como memoria colectiva es una representación del pasado, o del presente, no auspiciada por instituciones estatales sino generada por comunidades particulares. El recuerdo puede oponerse al discurso oficial y la memoria dominante. Suele contener un pasado reivindicativo aunque estilizado con la intención de ser aceptado por la mayor audiencia posible y poder convertirse en memoria hegemónica con la intención de disputarle su lugar a la memoria institucional.

\section{Conclusión}

Tras estudiar casos particulares de videojuegos históricos o de contenido histórico entendidos como memorias oficiales o colectivas que pueden ser, a la vez, memorias fuertes, débiles, literales o ejemplares, consideramos haber alcanzado el éxito en nuestro objetivo: demostrar que el videojuego histórico o de contenido histórico es memoria y no historia. No puede ser historia porque no cuentan con un ideal de verdad y su desarrollo no está movido por un interés de curiosidad. Todos los títulos aquí mentados tienen distintas intenciones particulares, nacionalistas, colectivas o individuales. Tampoco son historia porque no acuden a fuentes primarias ni están insertos en un contexto general. Gran parte de sus fuentes para reconstruir el momento histórico se encuentran en los medios de comunicación de masas. No logran ser historia porque los videojuegos históricos o de contenido histórico confunden narración histórica (la puesta en historia a través de un relato) con ficción histórica (invención literaria del pasado). Así hemos podido comprobarlo en el caso de Call of Duty: WWII y su recuerdo del exterminio judío o los crímenes de la Wehrmacht, así como en la falta total de contexto de 1979 Revolution. Y es que, de acuerdo a Traverso: «el historiador no puede esquivar el problema de la "puesta en texto» de su construcción del pasado, pero jamás podrá, si pretende hacer historia, arrancarla de su irreductible pedestal fáctico», ${ }^{87}$ un pedestal fáctico, de pruebas y documentos insertados en un relato con pretensión de verdad y universal que no existe en el videojuego hasta el momento.

87. E. Traverso, El Pasado...op. cit., 65. 